New Zealand Journal of Employment Relations, 46(1): 1-22

\title{
Top Executives Work-Life Balance, Job Burnout and Turnover Intentions: Moderated-Mediation with Knowledge Sharing Culture
}

\author{
JARROD HAAR*, URS DAELLENBACH ${ }^{* *}$, CONOR O’KANE $^{* * *}$, KATHARINA \\ RUCKSTUHL $^{* * * *}$ and SALLY DAVENPORT ${ }^{* * * *}$
}

\begin{abstract}
New Zealand top executives are seldom explored, and this paper examines the role of work-life balance (WLB) on top executives' turnover intentions, with job burnout mediating this relationship. It is expected that top executives with strong WLB will be aided with stronger wellbeing (lower burnout) and stronger work behaviours (lower turnover). Beyond these relationships, knowledge sharing culture (KSC) is included as a moderator and combined, a moderated mediation model is tested. Using data from 126 New Zealand top executives, we find that WLB negatively related to emotional exhaustion, cynicism, and turnover intentions, with cynicism fully mediating the influence of WLB on turnover intentions. A significant moderated mediation effect is found, which indicates that the indirect effect of WLB on turnover intentions through cynicism did vary, with the indirect effect diminishing as KSC becomes stronger. At levels above $0.2 \mathrm{SD}$ of KSC, WLB no longer has a significant effect on turnover. The findings add new insights into understanding turnover intentions in New Zealand, especially around boundary conditions of KSC, and highlight the complexity of executive talent retention.
\end{abstract}

Keywords: top executives; turnover intentions; work-life balance; job burnout; moderated mediation.

\section{Introduction}

As a research field, employee turnover has garnered much attention over many decades, including metaanalyses (Tett \& Meyer 1993; Griffeth et al., 2000). A continual area of focus for turnover researchers has been executives (e.g., Hom et al., 2008), due to the 'war for talent' (Pfeffer, 2001) and the high cost of turnover. Top executives are in those positions to facilitate better organisational performance and, consequently, are likely to be the most expensive human resources within organisations. Therefore, it is vital for Human Resource Management (HRM) to understand top talent turnover and associated retention factors. In New Zealand, executives represent the highest paid employees, with Careers New Zealand (2021) reporting that public sector chief executives earn between $\$ 120-700$ thousand annually, and a few earning more than $\$ 1$ million. Such roles earn between $\$ 120,000$ and $\$ 1$ million in the private sector, with

\footnotetext{
* Professor, Department of Management, AUT University, Auckland, New Zealand

** Professor, School of Management, Victoria University of Wellington, New Zealand

*** Assoc. Professor, Otago Business School, University of Otago, Dunedin, New Zealand

***** Assoc. Dean, Otago Business School, University of Otago, Dunedin, New Zealand

***** Professor, School of Management, Victoria University of Wellington, New Zealand
}

Acknowledgement: This study was funded by the New Zealand National Science Challenge: Science for Technological Innovation [Kia kotahi mai-Te Ao P_utaiao me Te Ao Hangarau]. 
a few paid even more. Despite this high level of remuneration, our understanding of what keeps them in their jobs is largely unknown.

Furthermore, there is lack of attention towards turnover intention and, similarly, little attention is given to the links with executive wellbeing, despite an EY (2015) study of 9700 employees from eight countries showing work-life balance (WLB) issues were prominent. Research has shown that WLB is a key factor in employee wellbeing (Haar, 2013; Brough et al., 2014), and there is evidence that leaders play an important role in shaping the WLB of others (Braun \& Peus, 2018; Haar et al., 2019). Indeed, there are links between WLB and employee turnover (Brough et al., 2014; Haar \& Brougham, 2020), making this pertinent to the present study. However, we do not know what role WLB might play in retaining top executives. Beyond these factors, we also explore the role of job burnout. Research has highlighted the importance of studying job burnout amongst leaders (Roche \& Haar, 2013) and combined, the present study examines turnover intentions and the role that wellbeing (WLB and job burnout) play.

Our final factor explored relates to the organisational environment in which top executives operate. Knowledge sharing culture (KSC) refers to an organisational culture where knowledge sharing is viewed positively and occurs across the breadth of an organisation (Husted et al., 2012). The present study includes KSC as a moderator and suggests that it may play a beneficial role in aiding top executive wellbeing and turnover intentions. Overall, the present study makes several contributions. First, examining WLB as a determinant of turnover intentions amongst top executives, and the role of job burnout (emotional exhaustion and cynicism) as mediators has not previously been tested. Second, we extend the literature by considering the context of KSC and test this as a moderator of the influence of WLB on outcomes. Finally, we test a moderated mediation model to determine whether KSC acts as a boundary condition and tempers the indirect effect of WLB on turnover intentions through job burnout. Our study model is shown in Figure 1.

\section{Figure 1. Study Model}

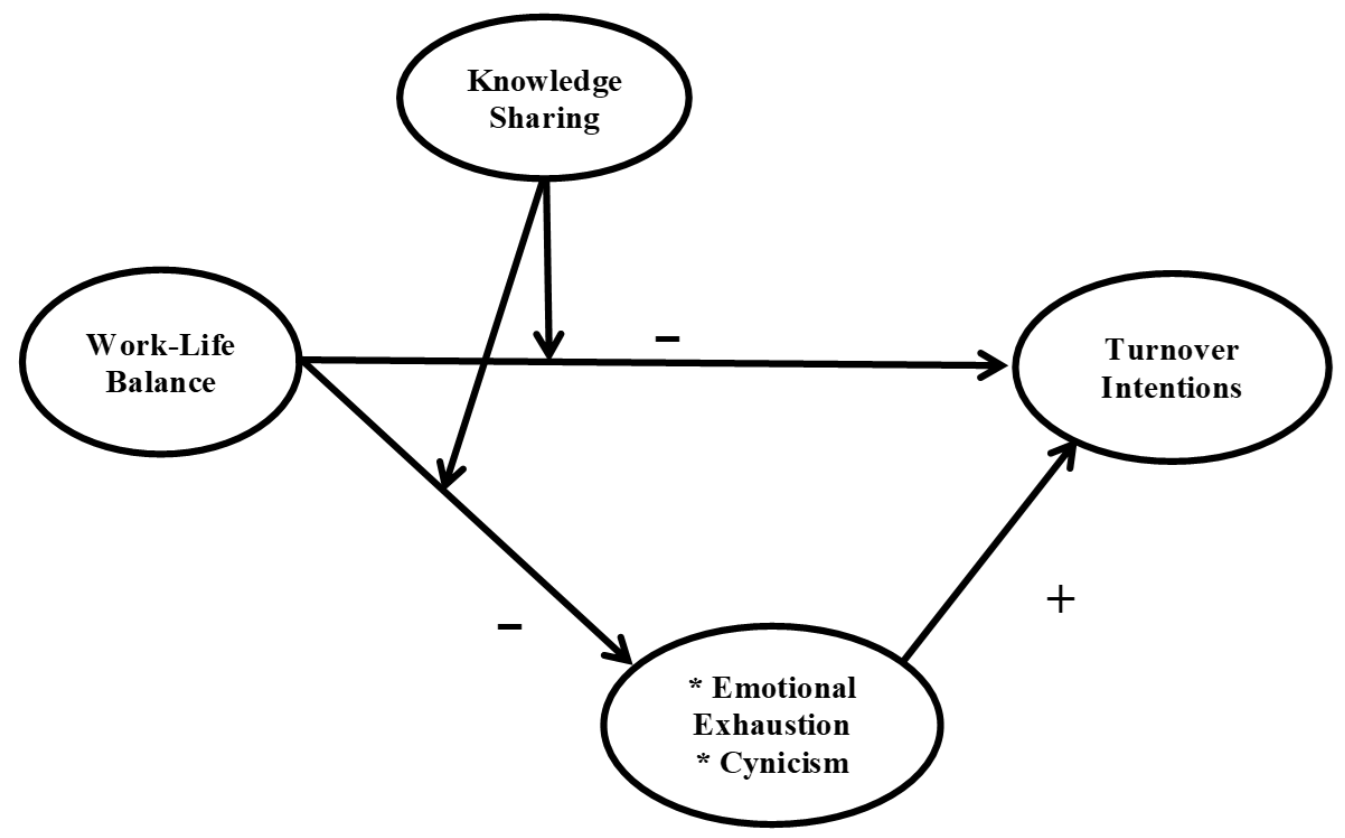


New Zealand Journal of Employment Relations, 46(1): 1-22

\section{Conservation of Resources Theory}

The Conservation of Resources (COR) theory (Hobfoll, 2002) is the theoretical lens used for understanding the links between WLB, job burnout and turnover intentions. COR theory is an integrated model of stress, which focuses on resources, which Hobfoll (2001) defined as "personal characteristics, conditions, or energies that are valued in their own right, or that are valued because they act as conduits to the achievement or protection of valued resources" (p. 339). COR focuses on how employees maintain, acquire, and lose resources (Hobfoll, 2001), and their reactions to such events (e.g., resource loss). Resources are broad and include time; Hobfoll (2001) identifies time broadly, including the time for work, time with loved ones, quality sleep-time and free time. Under COR theory, resources help shape employee perceptions (Hobfoll, 2002), which aligns with theoretical conceptualisations of WLB (Haar 2013). Theoretically, individuals with high WLB represent employees with more resources that can be used to manage the demands and pressures, in this case, of being a top executive. Thus, under COR theory, high WLB should enable top executives to better manage their wellbeing and reduce turnover intentions. The next section presents our key constructs and hypotheses.

\section{Work-Life Balance}

Haar (2013) noted that WLB is not a 50/50 breakdown between roles, but rather assumes a personal assessment of how multiple roles are balanced. Consequently, high WLB reflects a personal evaluation that role management is strong and positive. This person-centric approach has become the dominant approach (e.g., Russo et al., 2016; Brough et al., 2014) and strong support has been found for WLB influencing job outcomes like job satisfaction (Braun \& Peus, 2018; Haar et al., 2017; 2019) and wellbeing (Russo et al., 2016). A few studies have examined turnover intentions on employees (e.g., Surienty et al., 2014; Haar \& Brougham, 2020), and Brough et al. (2014) examined and find support for WLB influencing turnover intentions using Australian and New Zealand samples. Importantly, the context of these empirical studies has excluded top executives, and here we make a strong contribution. Given the argument that WLB is a major workplace issue and one reason identified for why people leave their jobs (EY, 2015), it is expected that top executives with high WLB will have more resources under COR theory to balance the roles between work and non-work, diminishing their turnover intentions. Overall, we expect top executives with high WLB to be less inclined to leave their job. We hypothesise the following.

\section{Hypothesis 1. WLB will be negatively related to turnover intentions.}

\section{Job Burnout}

Roche and Haar (2013) argued that job burnout is likely more prevalent for leaders due to the complex and challenging nature of the business environment. Maslach and Jackson (1981) define emotional exhaustion as "feelings of being emotionally overextended and exhausted" (p. 101), while cynicism refers to having an indifferent attitude towards one work and being cynical about the contribution of one's job (Euwema et al., 2004). We focus only upon these two factors of job burnout because they are the core dimensions (Euwema et al., 2004). Under COR theory, emotional exhaustion represents a chronic state of depletion (Wright \& Cropanzano, 1998), which might occur when there is too much demand for an employee's resources (e.g., low WLB). Thus, a top executive experiencing fatigue and exhaustion from their job likely represents someone with insufficient resources, making them more inclined to search for 
job alternatives. For example, dealing with major organisational issues that leave an executive exhausted at the start of the day might be the ultimate driver that makes them decide to quit their job.

However, similar to the beneficial influence on turnover behaviour, we expect an executive with high WLB to be sufficiently resourced to better manage the issues of their role, making them less prone to experience emotional exhaustion. In effect, having high WLB provides the executive with the time, focus, and energy to manage emerging issues (as a leader), which would exhaust a less-resourced executive (i.e., someone with low WLB). Dean et al. (1998) refer to cynicism as a negative mood targeting an organisation, with disparaging and critical behaviours. Under the COR theory, employees with greater WLB should have higher energy and time resources to better manage the potential energy drain from their roles, making them more content and less cynical. Thus, executives with greater resources via high WLB can spend more time finding business solutions that ultimately build a better understanding of their contribution to the organisation and the worth of their job.

There is some empirical support at present regarding the links between WLB and job burnout. UmeneNakano et al. (2013) found that WLB issues were positively related to emotional exhaustion and cynicism, while Haar (2013) found high WLB was related to lower emotional exhaustion in two samples of New Zealand employees. Similarly, Boamah and Laschinger (2016) found that WLB issues were positively related to both emotional exhaustion and cynicism. While these studies included professional workers, there was no specific focus on executives. Theoretically, we expect that high WLB will mean that executives are more likely to enjoy better wellbeing, as represented by low emotional exhaustion and low cynicism. We hypothesise the following.

\section{Hypotheses 2. WLB will be negatively related to (a) emotional exhaustion and (b) cynicism.}

We next consider the influential role of detrimental wellbeing on the turnover intentions of top executives. Leiter and Maslach (2009) argue this approach because the loss of resources from burnout are likely to shape behaviours towards leaving one's job, especially amongst leaders, with Roche and Haar (2013) stating "leaders are faced with mounting, unpredictable and conflicting demands" (p. 516). Thus, job burnout potentially captures the consequences of these pressures, and we explore the links to turnover. Under COR theory, executives, who feel greater resource loss through finding work emotionally draining and disbelief in their works worth, are more likely to seek to exit their organisation as a remedy to resource loss. Under COR theory, experiencing job burnout should encourage executives to consider turnover intentions. Using a sample of professional workers, Wright and Cropanzano (1998) found that emotional exhaustion was positively related to turnover intentions, and broadly, stress has meta-analytic support towards encouraging turnover (Griffeth et al., 2000). Hence, emotional exhaustion encourages seeking job alternatives. However, this remains largely untested in top executives despite them being more likely to suffer stress (Sharma \& Cooper, 2016). Similarly, Leiter and Maslach (2004) reported similar effects, noting that managers positions "come at the price of increased work demands beyond their expectations for the position" (p. 127).

Amongst nurses, Boamah and Laschinger (2016) found that both emotional exhaustion and cynicism were significantly related to turnover intentions, but it is cynicism that is often found to be the dominant predictor (e.g., Laschinger \& Fida 2014; Leiter \& Maslach, 2009). Despite the literature linking high burnout to executive positions (Sharma \& Cooper, 2016; Leiter \& Maslach, 2004), there is a dearth of studies exploring its link to turnover intentions amongst top executives. Overall, we suggest that not only will job burnout influence turnover intentions, but it will also mediate the influence of WLB on turnover 
New Zealand Journal of Employment Relations, 46(1): 1-22

intentions. Again, mediation effects are common in the literature (Leiter \& Maslach, 2009) as job burnout represents the final step from work resources (e.g., WLB) towards shaping turnover intentions. However, it is unknown whether this mediating effect holds for those in top executive positions. Perhaps these individuals perceive burnout as 'part for the position' and thus does not act as a mediator as we might otherwise expect? Theoretically, we would expect job burnout to mediate, representing that WLB minimises the drain of resources leading to less job burnout, which in turn leads to lower turnover intentions. This leads to the following hypotheses.

Hypotheses 3. (a) emotional exhaustion and (b) cynicism will be related to turnover intentions.

Hypothesis 4. Job burnout will mediate the influence of WLB on turnover intentions.

\section{Knowledge Sharing Culture as a Boundary Condition}

Finally, we add an organisational factor to contextualise the relationships between wellbeing and turnover. Knowledge can be a prime source of competitive advantage (Danskin et al., 2005), and, therefore, it is important that knowledge as a resource is shared. Husted and Michailova (2002) suggest that organisations can encourage and stimulate knowledge sharing. This can generate a KSC, with Husted et al. (2012) defining this as a culture where organisational members share knowledge across departments, and the organisation valuing this sharing positively. When KSC are high, there is a free-flowing of ideas and knowledge throughout an organisation. Under the COR theory, such an approach should provide executives with not only knowledge resources, such as information and insights, but also provide more resources around respect and professional development, which aligns with Hobfoll's (2001) list of resources. Hence, under COR theory, this can provide executives with resources that should enable and leverage the benefits of managing roles (e.g., WLB) and ultimately reduce job burnout issues and quit intentions. For example, understanding wider organisational issues might reduce cynicism around doubting the significance of work, and further improve turnover intentions.

We test KSC as a potential moderator on the influence of WLB and suggest that this will intensify the beneficial links between WLB and job burnout. We propose that the additional resources from high KSC will be leveraged with high WLB leading to lower burnout because sharing ideas and interacting with others within an organisation is likely to reinforce the value of what an executive does, leaving them less cynical when they have more resources (high WLB). Similarly, under COR, we suggest high KSC should provide more resources (e.g., where to access needed human resources practices), and this should lead to lower emotional exhaustion. Here, the resources gained by KSC align with Hobfoll's (2001) resources around having a leadership role and engaging with organisational members. Thus, KSC acts as a resource gain and leads to lower emotional exhaustion. We expect similar advantages towards turnover intentions, with high KSC providing information resources that clarify issues around decision making (e.g., staying) and, thus, help retention decisions due to greater psychological resources (e.g., confidence, business insights). For example, understanding future opportunities in the organisation might enable the reevaluation of turnover thoughts. We suppose the top executive is in a useful position to rate the overall climate of the organisation around knowledge sharing.

Finally, we combine these factors and test KSC as a moderator on the mediated relationships and suggest that KSC is likely to act as a boundary condition, whereby the effectiveness of WLB on turnover intentions - through job burnout - fluctuates with KSC. Hayes (2018) notes that the analytic approaches of 
moderation and mediation can be combined and calls this moderated-mediation. It is defined as "an analytical strategy focused on quantifying the boundary conditions of mechanisms and testing hypotheses about the contingent nature of processes... whether an indirect effect (mediation) is dependent on another variable (moderation)" (Hayes, 2018, p. 5). We posit that KSC will play a positive intensifying role, whereby we expect the strength of the indirect effect of WLB on job burnout to reduce when KSC gets stronger, as executives are likely to draw greater resources through the organisation (through KSC) than relying on their own personal resources (WLB). Ultimately, KSC will shape the way balance enables staying behaviours, and we posit the following two-way and moderated mediated hypotheses.

Hypothesis 5. KSC will moderate the influence of WLB on (a) emotional exhaustion, $(b)$ cynicism, and (c) turnover intentions.

Hypotheses 6: The indirect relationship between $W L B$ and turnover intentions via (a) emotional exhaustion and $(b)$ cynicism will be moderated by KSC, such that the indirect effect of WLB becomes weaker as KSC gets stronger (moderated mediation).

\section{Methods}

\section{Participants and Sample}

In 2017, a Qualtrics survey panel of New Zealand top executives was undertaken, which resulted in 127 participants being recruited. A filter question confirmed respondents' managerial position, and we focus solely on those in a senior executive role (e.g., CEO, HR Manager, CFO etc.). Qualtrics panel provides all participants' confidentiality, with their identities kept anonymous. Qualtrics removes respondents completing the survey at a pace that is too slow or fast; this approach to data collection has yielded useful samples (e.g., Haar et al., 2018). A recent meta-analysis by Walter et al., (2018) showed that panel data was comparable with conventionally sourced data.

Overall, respondents were more likely to be male (61 per cent), ranging from 30-65 years, with an average age of 46.7 years $(S D=12.6)$. Hours worked averaged 42.6 hours per week ( $S D=12.4$ hours). By tenure, the average time in their current role was 9.8 years ( $\mathrm{SD}=6.9$ years).By education, the majority had a university degree or a postgraduate qualification like an MBA (39 per cent and 25 per cent, respectively). By ethnicity, 70 per cent were New Zealand European, and the majority ( 88 per cent) were from the private sector. The respondents were well spread by industry, ranging from agriculture, education, health care, and manufacturing to professional services, retail, tourism, telecommunications, and technology.

\section{Measures}

Work-Life Balance was measured using the three-item measure by Haar (2013), coded 1=strongly disagree, 5=strongly agree. A sample item is "I manage to balance the demands of my work and personal/family life well" $(\alpha=.92)$.

Knowledge Sharing Culture was measured using the three-item measure by Husted et al. (2012), coded $1=$ strongly disagree, $5=$ strongly agree. A sample item is "My company's values and attitudes support knowledge sharing" $(\alpha=.82)$. 
New Zealand Journal of Employment Relations, 46(1): 1-22

Emotional Exhaustion and Cynicism were each measured using three items from Maslach and Jackson (1981), coded 1=never, 5=every day. A sample item for emotional exhaustion is "I feel emotionally drained from my work" $(\alpha=.90)$, and a sample item for cynicism is "I have become more cynical about whether my work contributes anything" $(\alpha=.83)$.

Turnover Intentions were measured using the four-item measure by Kelloway et al., (1999), coded $1=$ strongly disagree, 5=strongly agree. A sample item is "I intend to ask people about new job opportunities" $(\alpha=.96)$.

We controlled for factors typical of the literature. Specifically, how job mobility can impact on turnover (Harvey \& Martinko, 2009). Job Mobility was measured using the two-item construct by Tepper (2000), coded 1=strongly disagree, 5=strongly agree. A sample item is "If I were to quit my job, I could find another job that is just as good". Another item was added to improve the psychometric properties of the construct "In my region, there is a shortage of workers in my field". An exploratory factor analysis (principal components, varimax rotation) confirmed the items all loaded onto a single factor with eigenvalues greater than 1 (1.951), accounting for sizeable amounts of the variance (65 per cent) and achieved adequate reliability $(\alpha=.72)$. In addition, we controlled for Job Tenure (years) and Age (in years) as meta-analysis (Griffeth et al., 2000) supports their inclusion. We also controlled for Hours Worked (per week) as there is meta-analytic support ( $\mathrm{Ng} \&$ Feldman, 2008) between long hours worked and more positive occupational outcomes. We also included Gender $(1=$ female, $0=$ male $)$ because this is common in the work-family field (e.g., Haar, 2013). Finally, we controlled for Firm Size (number of employees) as we expect larger sized firms are more likely to provide more opportunities and challenges for executive managers and be negatively related to turnover intentions. Due to skewness issues, we follow Haar and White (2011) and log transform firm size to induce normality.

Analysis

Hypotheses were tested using PROCESS version 3.1 (in SPSS version 25), at the 95 per cent confidence interval and bootstrapping at 5,000. We use model 8 to test for direct, mediation and moderation effects, as well the Index of Moderated Mediation.

\section{Measurement Model}

Using AMOS version 25, we conducted a CFA (Confirmatory Factor Analysis) in Structural Equation Modelling (SEM) on our core model constructs, following Williams et al., (2009) regarding model fit: (1) the comparative fit index (CFI $\geq .95)$, (2) the root-mean-square error of approximation (RMSEA $\leq .08)$, and (3) the standardised root mean residual (SRMR $\leq .10)$. The hypothesised measurement model and three alternative models are shown in Table 1. 
Table 1. Results of Confirmatory Factor Analysis

\begin{tabular}{|c|c|c|c|c|c|c|c|c|c|}
\hline \multirow[b]{2}{*}{ Model } & \multicolumn{3}{|c|}{ Model Fit Indices } & \multicolumn{6}{|c|}{ Model Differences } \\
\hline & $\chi^{2}$ & Df & CFI & RMSEA & SRMR & $\Delta \chi^{2}$ & $\Delta \mathbf{d f}$ & $\mathbf{p}$ & Details \\
\hline Model 1 & 176.5 & 137 & .978 & .048 & .048 & & & & \\
\hline Model 2 & 286.7 & 142 & .919 & .090 & .069 & 110.2 & 5 & .001 & Model 1 to 2 \\
\hline Model 3 & 281.8 & 142 & .922 & .088 & .084 & 105.3 & 5 & .001 & Model 1 to 3 \\
\hline Model 4 & 271.2 & 142 & .928 & .085 & .080 & 94.7 & 5 & .001 & Model 1 to 4 \\
\hline
\end{tabular}

Model 1= Hypothesised 6-factor model: work-life balance, knowledge sharing culture, emotional exhaustion, cynicism, job mobility and turnover intentions.

Model 2= Alternative 5-factor model: work-life balance, knowledge sharing culture, emotional exhaustion and cynicism combined, job mobility and turnover intentions.

Model 3= Alternative 5-factor model: work-life balance and knowledge sharing culture combined, emotional exhaustion, cynicism and turnover intentions.

Model 4= Alternative 5-factor model: work-life balance, knowledge sharing culture, emotional exhaustion, cynicism, job mobility and turnover intentions combined. 
Overall, the hypothesised measurement model was the best fit for the data: $\chi^{2}(137)=176.5$ $(\mathrm{p}=.000), \mathrm{CFI}=.978, \mathrm{RMSEA}=0.048$ and $\mathrm{SRMR}=0.048$, with the hypothesised model being significant (all $\mathrm{p}<.001$ ) compared to alternative measurement constructs (Hair et al., 2010).

\section{Results}

Descriptive statistics for the study variables are shown in Table 2. 


\section{Table 2. Correlations and Descriptive Statistics of Study Variables}

\begin{tabular}{|c|c|c|c|c|c|c|c|c|c|c|c|c|}
\hline Variables & $\mathrm{M}$ & SD & 1 & 2 & 3 & 4 & 5 & 6 & 7 & 8 & 9 & 10 \\
\hline 1. Age & 47.7 & 12.6 & -- & & & & & & & & & \\
\hline 2. Job Tenure & 9.8 & 6.9 & $.59 * *$ & -- & & & & & & & & \\
\hline 3. Hours Worked & 42.6 & 12.4 & -.03 & -.03 & -- & & & & & & & \\
\hline 4. Job Mobility & 3.2 & .93 & -.11 & -.06 & .01 & -- & & & & & & \\
\hline 5. Firm Size & 246 & 1080 & $-.38 * *$ & $-.25 * *$ & $.36 * *$ & $.19 *$ & -- & & & & & \\
\hline 6. Work-Life Balance & 3.7 & .95 & -.03 & .12 &.$-.20 *$ & .09 & .05 & $(.95 / .87)$ & & & & \\
\hline 7. $\mathrm{KSC}$ & 3.5 & .93 & -.16 & .03 & .00 & .05 & .01 & $.44 * *$ & $(.86 / .68)$ & & & \\
\hline 8. Emotional Exhaustion & 2.4 & 1.1 & -.11 & $-.21 * *$ & $.29 * *$ & .14 & -.07 & $-.54 * *$ & $-.22 *$ & $(.94 / .83)$ & & \\
\hline 9. Cynicism & 2.1 & 1.1 & -.14 & $-.20 * *$ & .08 & $.20^{*}$ & -.04 & $-.36 * *$ & $-.41 * *$ & $.67 * *$ & $(.90 / .76)$ & \\
\hline 10. Turnover Intentions & 2.4 & 1.4 & $-.36 * *$ & $-.28 * *$ & -.02 & $.32 * *$ & $.31 * *$ & $-.20 *$ & $-.25 * *$ & $.40 * *$ & $.62 * *$ & $(.97 / .89)$ \\
\hline
\end{tabular}

$\mathrm{N}=127, * \mathrm{p}<.05, * * \mathrm{p}<.01$. Note: $(\mathrm{)}=$ Diagonal entries are composite reliability estimates and the square roots of the average variance extracted. 
Table 2 shows that WLB is significantly correlated with emotional exhaustion $(\mathrm{r}=-.54, \mathrm{p}<.01)$, cynicism $(\mathrm{r}=-.36, \mathrm{p}<.01)$, turnover intentions $(\mathrm{r}=-.20, \mathrm{p}<.05), \mathrm{KSC}(\mathrm{r}=.44, \mathrm{p}<.01)$, and hours worked $(\mathrm{r}=-.20$, $\mathrm{p}<.05)$. Turnover intentions are significantly correlated with emotional exhaustion $(\mathrm{r}=.40, \mathrm{p}<.01)$, cynicism $(\mathrm{r}=.62, \mathrm{p}<.01), \mathrm{KSC}(\mathrm{r}=-.25, \mathrm{p}<.01)$, job mobility $(\mathrm{r}=.32, \mathrm{p}<.01)$, job tenure $(\mathrm{r}=-.28, \mathrm{p}<.01)$, and age $(r=-.36, p<.01)$. Finally, KSC is significantly correlated with emotional exhaustion $(r=-.22, p<$ $.05)$ and cynicism $(r=-.41, \mathrm{p}<.01)$, and these job burnout dimensions correlate highly with each other $(\mathrm{r}=$ $.67, \mathrm{p}<.01)$.

Results of the direct, mediation, moderation and moderated regression analysis towards turnover intentions is presented in Table 3. 
Table 3. Results of Moderated-Mediated Regression Analyses

\begin{tabular}{|c|c|c|c|}
\hline Variables & $\mathrm{B}(\mathrm{SE})$ & Confidence Intervals & p-value \\
\hline \multicolumn{4}{|l|}{ Controls: } \\
\hline Hours Worked $\rightarrow$ EE & $.01(.00)$ & $\mathrm{LL}=.00, \mathrm{LU}=.03$ & .0436 \\
\hline Job Mobility $\rightarrow$ EE & $.19(.09)$ & $\mathrm{LL}=.04, \mathrm{LU}=.33$ & .0350 \\
\hline Job Tenure $\rightarrow$ EE & $-.03(.01)$ & $\mathrm{LL}=-.05, \mathrm{UL}=-.01$ & .0245 \\
\hline Job Mobility $\rightarrow$ Cynicism & $.25(.09)$ & $\mathrm{LL}=.09, \mathrm{LU}=.41$ & .0093 \\
\hline Job Tenure $\rightarrow$ Cynicism & $-.03(.01)$ & $\mathrm{LL}=-.06, \mathrm{LU}=-.01$ & .0169 \\
\hline Job Mobility $\rightarrow$ Turnover Intentions & $.21(.11)$ & $\mathrm{LL}=.04, \mathrm{LU}=.39$ & .0448 \\
\hline Hours Worked $\rightarrow$ Turnover Intentions & $-.02(.01)$ & $\mathrm{LL}=-.03, \mathrm{UL}=-.00$ & .0328 \\
\hline Firm Size $\rightarrow$ Turnover Intentions & $.13(.06)$ & $\mathrm{LL}=.03, \mathrm{LU}=.23$ & .0296 \\
\hline \multicolumn{4}{|l|}{ Predictor: } \\
\hline WLB $\rightarrow$ Turnover Intentions & $-.41(.11)$ & $\mathrm{LL}=-.63, \mathrm{LU}=-.18$ & .0000 \\
\hline Effect After Mediators: & $-.07(.13)$ & $\mathrm{LL}=-.29, \mathrm{LU}=.14$ & .5611 \\
\hline $\mathrm{WLB} \rightarrow \mathrm{EE}$ & $-.54(.10)$ & $\mathrm{LL}=-.70, \mathrm{LU}=-.38$ & .0000 \\
\hline WLB $\rightarrow$ Cynicism & $-.27(.10)$ & $\mathrm{LL}=-.44, \mathrm{LU}=-.10$ & .0113 \\
\hline \multicolumn{4}{|l|}{ Mediators: } \\
\hline $\mathrm{EE} \rightarrow$ Turnover Intentions & $-.08(.14)$ & $\mathrm{LL}=-.30, \mathrm{LU}=.15$ & .7111 \\
\hline Cynicism $\rightarrow$ Turnover Intentions & $.67(.13)$ & $\mathrm{LL}=.46, \mathrm{LU}=.88$ & .0000 \\
\hline \multicolumn{4}{|l|}{ Moderator: } \\
\hline $\mathrm{KSC} \rightarrow \mathrm{EE}$ & $-.02(.09)$ & $\mathrm{LL}=-.18, \mathrm{LU}=.15$ & .8621 \\
\hline KSC $\rightarrow$ Cynicism & $-.30(.11)$ & $\mathrm{LL}=-.48, \mathrm{LU}=-.12$ & .0061 \\
\hline KSC $\rightarrow$ Turnover Intentions & $-.09(.12)$ & $\mathrm{LL}=-.29, \mathrm{LU}=.12$ & .4810 \\
\hline \multicolumn{4}{|l|}{ Interactions: } \\
\hline WLB $\times$ KSC $\rightarrow$ EE & $.19(.07)$ & $\mathrm{LL}=.06, \mathrm{LU}=.31$ & .0141 \\
\hline WLB x KSC $\rightarrow$ Cynicism & $.18(.08)$ & $\mathrm{LL}=.04, \mathrm{LU}=.31$ & .0314 \\
\hline WLB x KSC $\rightarrow$ Turnover Intentions & $.03(.09)$ & $\mathrm{LL}=-.12, \mathrm{LU}=.18$ & .7111 \\
\hline Index of Moderated Mediation (EE) & $-.01(.03)$ & $\mathrm{LL}=-.07, \mathrm{LU}=.03$ & .3694 \\
\hline Index of Moderated Mediation (Cynicism) & $.12(.07)$ & $\mathrm{LL}=.02, \mathrm{LU}=.24$ & .0432 \\
\hline \multirow[t]{3}{*}{ Total Variance $\left(\mathrm{r}^{2}\right)$} & & $\mathrm{EE}$ & .43 \\
\hline & & Cynicism & .34 \\
\hline & & Turnover Intentions & .51 \\
\hline
\end{tabular}


The results show that WLB is significantly related to turnover intentions $(\beta=-.41(.11), \mathrm{p}=.0000[\mathrm{LL}=-$ $.63, \mathrm{UL}=-.18])$, emotional exhaustion $(\beta=-.54(.10), \mathrm{p}=.0000[\mathrm{LL}=-.70, \mathrm{UL}=-.38])$, and cynicism $(\beta=-$ $.27(.10), \mathrm{p}=.0113[\mathrm{LL}=-.44, \mathrm{UL}=-.10])$, supporting Hypothesis $1,2 \mathrm{a}$ and $2 \mathrm{~b}$. Furthermore, while emotional exhaustion is not significantly related to turnover intentions $(\beta=-.08(.14), \mathrm{p}=.7111[\mathrm{LL}=-.30$, $\mathrm{UL}=.15])$ but cynicism is significantly related $(\beta=.67(.13), \mathrm{p}=.0000[\mathrm{LL}=.46, \mathrm{UL}=.88])$, and when these job burnout dimensions are included in the model, it fully mediates the effect of WLB on turnover intentions: $(\beta=-.07(.13), p=.5611[\mathrm{LL}=-.29, \mathrm{UL}=.14])$. These findings support Hypotheses $3 \mathrm{~b}$ and 4 . Examining the indirect effects (Hayes, 2018) shows that WLB is still significant on turnover intentions in the presence of cynicism $(\beta=-.26(.10), \mathrm{p}=.0050[\mathrm{LL}=-.46, \mathrm{UL}=-.07])$.

The next set of Hypotheses relate to KSC interacting with WLB, and this was supported towards emotional exhaustion $(\beta=.19(.07), \mathrm{p}=.0091[\mathrm{LL}=.06, \mathrm{UL}=.31])$ and cynicism $(\beta=.18(.08), \mathrm{p}=.0314[\mathrm{LL}=.04$, $\mathrm{UL}=.31])$ but not turnover intentions $(\beta=.03(.09), \mathrm{p}=.7111[\mathrm{LL}=-.12, \mathrm{UL}=.18])$. Thus, we have support for Hypotheses $5 \mathrm{a}$ and $5 \mathrm{~b}$ but not $5 \mathrm{c}$. The results of the index of moderated mediation were found to be significant in the model through cynicism (Index= $.12(.07), \mathrm{p}=.0432[\mathrm{LL}=.02, \mathrm{UL}=.24]$ ) but not emotional exhaustion ( $\mathrm{p}>$.05), supporting Hypothesis 6b only. According to Hayes (2018), the interpretation of this effect means that indirect effect of cynicism on turnover intentions (which fully mediates the direct effects of WLB) differs between respondents with different knowledge sharing levels. To provide interpretation of the two-way moderating effects and moderated mediation effects, we present the graphed interactions (Figures 2-4).

Figure 2. Interaction Effects of Knowledge Sharing on WLB with Emotional Exhaustion as the Dependent Variable.

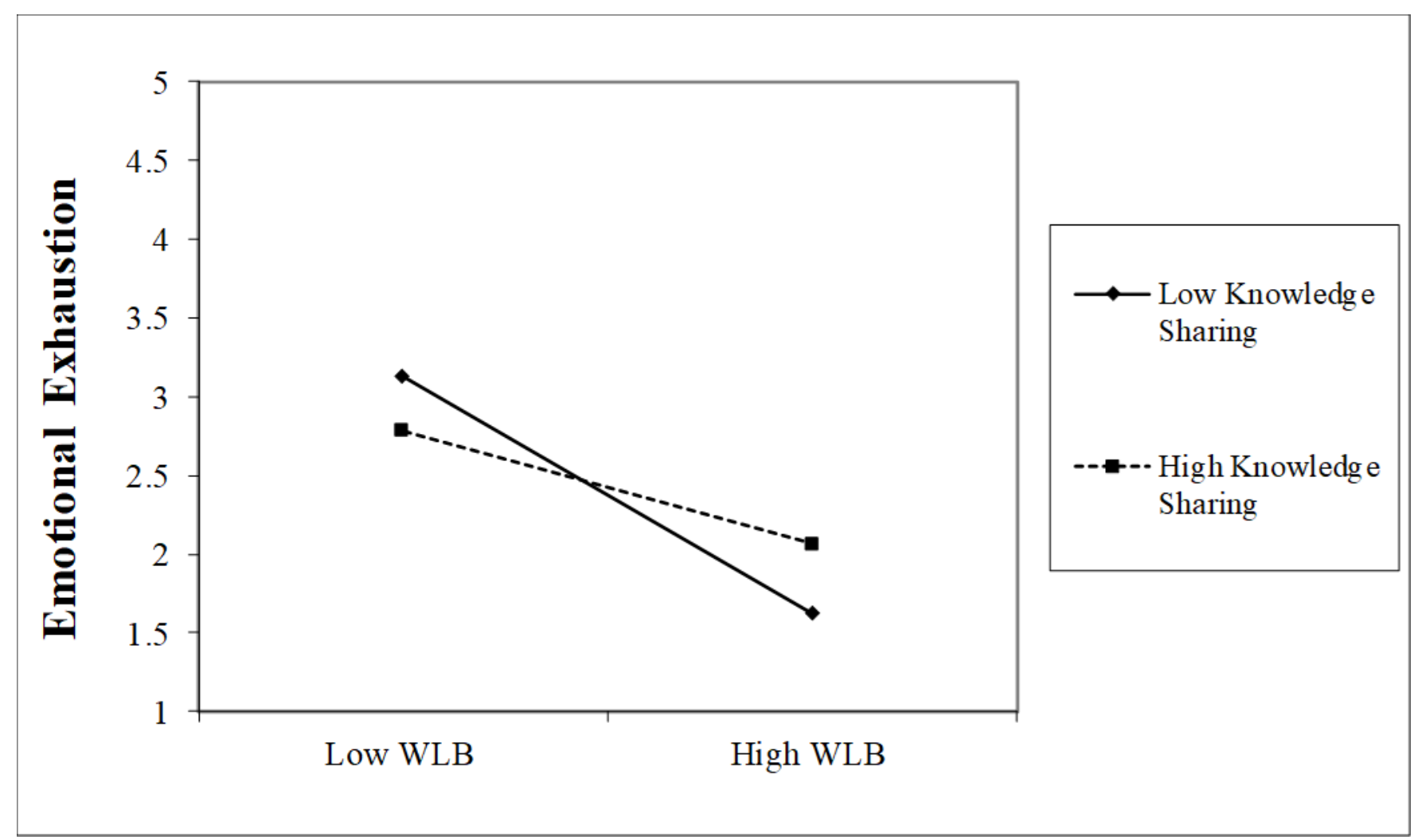


Figure 3. Interaction Effects of Knowledge Sharing on WLB with Cynicism as the Dependent Variable.

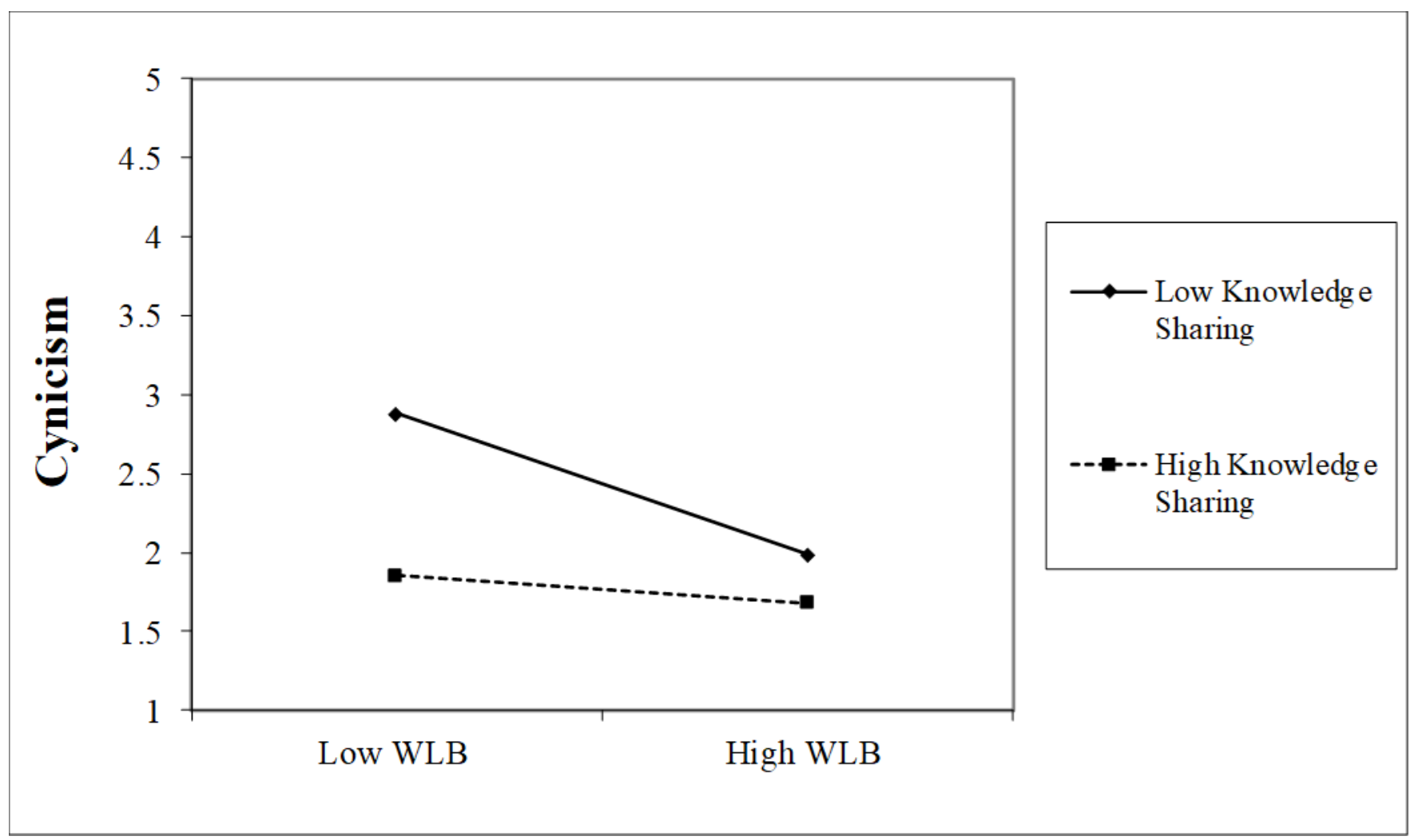

Figure 4. Indirect Effects of WLB on Turnover Intentions Through Cynicism conditional on Knowledge Sharing.

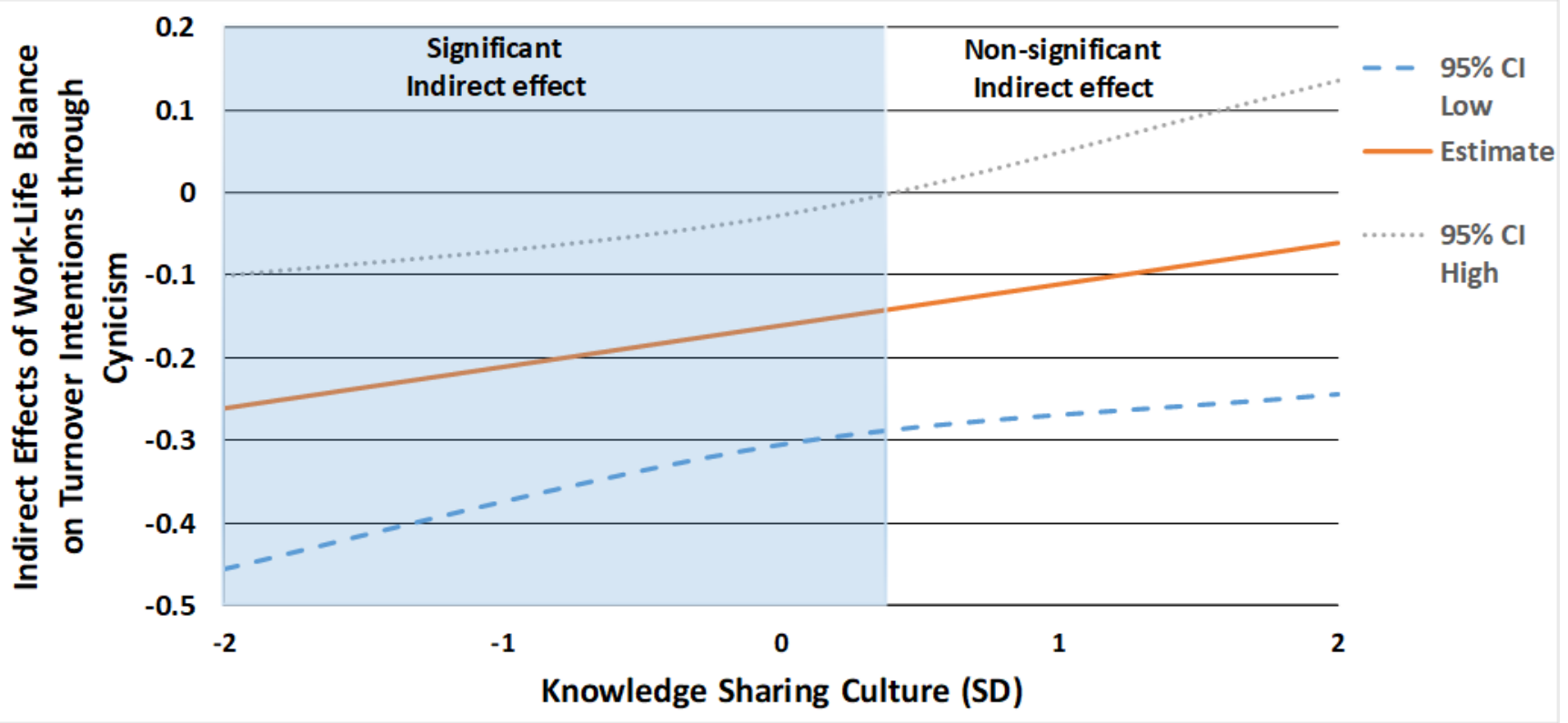


New Zealand Journal of Employment Relations, 46(1): 1-22

Figure 2 shows that at low levels of WLB, respondents report high levels of emotional exhaustion, with those reporting low knowledge sharing reporting the highest exhaustion. At high levels of WLB, all respondents report significantly lower emotional exhaustion, although those with high knowledge sharing report slightly higher levels than those with low knowledge sharing. This effect supports Hypothesis 5a because knowledge sharing was more detrimental at high levels than low levels. Figure 3 shows that at low levels of WLB, respondents report high levels of cynicism but only for those reporting low knowledge sharing. At high levels of WLB, respondents with low knowledge sharing report significantly lower cynicism, although those with high knowledge report continually flat (but low) levels of cynicism, at levels that are the lowest. This effect supports Hypothesis 5b because knowledge sharing was expected to be more beneficial in managing cynicism within a firm.

Regarding Hypothesis 6b (moderated mediation effect through cynicism), we follow the approach of Wayne et al., (2017). This involves probing the conditional indirect effect by examining the magnitude and significance of the indirect effect of WLB on turnover intentions through cynicism at the various levels of KSC. Figure 4 shows the significant indirect effect of WLB $\rightarrow$ cynicism $\rightarrow$ turnover intentions, conditional on the effects of KSC (at -2SD, mean, and +2SD). We find that, for those top executives working in firms with low KSC, the effect of WLB on turnover intentions vis-à-vis cynicism was strongly negative (estimate $=-.26, \mathrm{p}=.0017$; LLCI $=-.46 ; \mathrm{ULCI}=-.10$ ). The effect is also significant but modest for top executives working in firms with average KSC (estimate $=-.16, p=.0125 ; \mathrm{LLCI}=-.31$; ULCI = .03). However, for those top executives in firms with high KSC the effect of WLB on turnover intentions vis-à-vis cynicism was not statistically significant (estimate $=-.06, \mathrm{p}=.2595 ; \mathrm{LLCI}=-.24 ; \mathrm{ULCI}=.13$ ). This shows that, for top executives, the beneficial influence of WLB on turnover intentions becomes weaker as KSC becomes stronger. The indirect effect of WLB was only significant when KSC was at levels lower than 0.2 standard deviations above the mean or less. This supports our Hypothesis $6 \mathrm{~b}$.

Overall, the models account for large amounts of variance towards emotional exhaustion (43 per cent) and cynicism (34 per cent), and especially turnover intentions (51 per cent).

\section{Discussion}

The present study explored the influence of WLB on turnover intentions amongst a sample of top executives, and we find strong support aligned with the limited literature (Brough et al., 2014; Haar \& Brougham, 2020). While only a handful of studies have explored these linkages, there has been no exploration of top executives and, aligned with the EY (2015) study of 9700 employees highlighting that WLB is a prominent issue, we find the effects found within employees hold amongst those at the top echelon of the organisational chart. This aligns with our chosen COR theoretical approach, whereby top executives with superior balance between work and non-work roles (Haar, 2013) are more likely to have the resources (time, energy, enthusiasm) that enable them to focus on staying with their job (Hobfoll et al., 2018).

Beyond the effects of WLB on turnover, we also explored the influence on emotional exhaustion and cynicism. The limited literature showed support for WLB targeting emotional exhaustion only (e.g., Haar 
2013). The present study extended this approach to include cynicism, because disparaging thoughts about the workplace (Dean et al., 1998) may, especially, drive senior executives to leave their job. It was argued that being both emotionally exhausted from the job as well as having a critical sense of cynicism about the value of the work could encourage senior executives to consider leaving. We found that WLB was negatively related to both job burnout dimensions. Further, we found strong support for job burnout fully mediating the direct relationships between WLB and turnover intentions, which had previously been unexplored. While studies of WLB and turnover have explored and found support for mediators, such as job satisfaction (see Haar \& Brougham, 2020; Brough et al., 2014), this is the first to explore job burnout. Under COR theory, higher resources from superior WLB enable top executives to minimise their exhaustion and cynicism from their work roles, which, in turn, can shape turnover.

Indeed, the approach to include both emotional exhaustion and cynicism is important because we find cynicism is the key driver of turnover intentions, with emotional exhaustion being non-significant, which aligns with studies exploring job burnout as a mediator of work factors on turnover intentions (e.g., Leiter \& Maslach, 2009; Boamah \& Laschinger, 2016), although those studies did not target top executives. This might suggest that top executives understand that there are challenges with such roles, and that feeling exhausted and tired might be expected. However, once feelings of cynicism grow, and executives are left feeling indifferent about the contribution their job makes (Euwema et al., 2004), then they are much more likely to seek an end to their current roles. While studies of leaders and managers show that job burnout is especially high (e.g., Sharma \& Cooper, 2016; Leiter \& Maslach, 2004), this study is one of a handful to explore these burnout linkages amongst top executives.

From the COR theory approach, having greater resources due to WLB can reduce turnover intentions, but these are better understood as being grounded through cynicism. Thus, high WLB provides more resources, and, in turn, these can be used to minimise the cynical nature of work, which is the key driver of turnover intentions in our executive sample. Our finding that cynicism is the dominant job burnout dimension aligns well with studies (e.g., Laschinger \& Fida, 2014; Leiter \& Maslach, 2009), although we acknowledge other studies have found both burnout dimensions to be significant (e.g., Boamah \& Laschinger, 2016). Perhaps top executives who feel especially cynical about their work have reached a critical 'tipping point' whereby the job and organisation is no longer appealing - driving resignation thoughts.

Finally, our study also added an organisational factor to contextualise the potential role that knowledge sharing might play between WLB and job burnout and turnover intentions. While we found significant two-way interactions between WLB and KSC, the effects differed. Emotional exhaustion was lower at high levels of WLB, with effects slightly better for low KSC compared to high levels. This might suggest that KSC does come with an element of exhaustion intensification, perhaps indicating a psychological and emotional cost associated with knowledge sharing through having to share and engage with other people more often throughout an organisation. This also highlights that, in high KSC, it might be that top executives are expected to contribute highly. However, towards cynicism, the effects are much stronger and clearer. High levels of KSC are associated with respondents with low cynicism at all levels of WLB, although at high levels of WLB, respondents with low KSC have low levels of cynicism too. This shows that engagement with other workers appears to be an important factor for executives around reducing their cynicism through KSC. Given KSC was also significantly and negatively related to cynicism - our key turnover intention predictor - it also highlights new benefits to those already espoused around knowledge sharing (Husted \& Michailova, 2002; Husted et al., 2012). 
We also contribute to the turnover literature by testing KSC as a boundary condition, which such analyses being seldom explored in the literature. We found significant moderated mediation effects, highlighting that KSC plays an important role, with WLB being key to influencing turnover intentions via cynicism (as a mediator), but only at low and moderate KSC levels. In workplaces with high KSC, the indirect effect of WLB becomes nullified and non-significant, indicating that a boundary condition exists regarding the indirect effects of WLB as being conditional on KSC (when cynicism mediates). The moderated mediation analysis effects show that the influence of WLB on turnover intentions is not universal and those with stronger KSC (0.2 above the mean) register no significant indirect effect from WLB. Hence, we find that cultures with high knowledge sharing appear to provide sufficient resources to over-ride the otherwise beneficial effect of WLB on turnover intentions.

This moderated mediation effect provides major insights and sharper understanding of the role of WLB in the context of executives' turnover intentions. Studies identifying a boundary condition are growing (Hayes, 2018), and the present study helps us understand that the influence of WLB on the turnover intentions of executives might be limited, especially for those working in organisational cultures with high knowledge sharing, because that can over-ride the influence of WLB on turnover intentions, albeit in the context of cynicism. Importantly, WLB does shape cynicism - extending the current focus on emotional exhaustion (e.g., Haar, 2013) - and aligns with those not exploring WLB per se, but work-life issues (Umene-Nakano et al., 2013; Boamah \& Laschinger, 2016). Importantly, WLB still retains a significant indirect effect on turnover intentions, although this becomes less important at high KSC. This boundary condition is an important finding, as research shows the importance of cynicism towards turnover intentions (e.g., Laschinger \& Fida, 2014; Leiter \& Maslach, 2009) and can be extended to top executives. Further, the insight that knowledge sharing might play a vital role, at least for top executives, provides new knowledge and direction.

\section{HR Implications and Future Research}

Retaining top talent is vital for organisations - including cost and retaining institutional knowledge - and this might be especially important for top executives, who have high pay and, thus, represent a higher cost to their organisation when they leave. Therefore, retaining top executives can play a vital role in maintaining and extending business success, with meta-analysis (Park \& Shaw, 2013) showing that firms with higher quit rates perform poorly. We found that WLB plays a vital role in the retention of top executives, and thus HR managers should utilise WLB policies and support practices to help retain top executive talent. Recent research has shown the importance of leadership in shaping employee WLB (Haar et al., 2017, 2019), and there may be aspects that firms can develop and implement to provide greater WLB for executives. Despite this strong value around WLB, boundary condition findings indicate that organisations with a strong KSC might go the 'extra mile' in providing resources that benefit executive retention, and HR managers might seek to develop and encourage a stronger organisational culture around knowledge sharing to help minimise cynicism and aid retention. However, the detrimental two-way interaction effects of KSC on WLB towards emotional exhaustion does indicate that KSC should not be viewed as a panacea. A culture based on knowledge sharing is clearly complex if it comes with additional exhaustion effects. Given the direct effects of WLB in reducing emotional exhaustion and cynicism, greater attention to WLB is still needed. 
The findings also provide direction for researchers, particularly around exploring boundary conditions with KSC and within the WLB and turnover field, to gain stronger insights into relationships. Finding that the direct effect of WLB on turnover intentions through cynicism still had a significant indirect effect does support the use of indirect effects in mediation analysis (Hayes, 2018). We encourage further replication with other executive and non-executive samples to explore this effect in particular, as well as addressing other outcomes beyond turnover, like performance. Researchers could also examine turnover longitudinally to determine these effects on actual turnover. While the links between turnover intentions and actual turnover have meta-analytical support (Tett \& Meyer 1993), following the current model towards actual turnover would be a useful extension. Finally, researchers might consider testing additional resources under COR theory, such as individual personality (e.g., organisational-based self-esteem, e.g., Ghafoor \& Haar, 2020).

\section{Limitations}

The present study uses cross-sectional data, although the use of CFA in SEM alleviates this somewhat (Haar et al., 2018). This is because the alternative CFAs show the original hypothesised factor structures are a good fit to the data, which would be unlikely if common method variance (CMV) was an issue. Furthermore, Evans (1985) used Monte Carlo analysis to show that CMV is less likely when significant moderating effects are found, providing additional confidence. That said, we followed recommendations by Podsakoff et al., (2003) and conducted a Harman's One Factor Test as a post-hoc test of CMV. The unrotated factor analysis resulted in several factors, with the largest accounting for only 29.7 per cent of the variance, indicating CMV is not an issue. Finally, it must be acknowledged that the KSC construct was also reported by the top executive, and while they might be suitably positioned to capture knowledge climate in their organisation, the self-reported nature does make this potentially problematic.

\section{Conclusion}

Overall, the present study provides insights into the process of how WLB amongst the top executives can influence turnover intentions, specifically via the mediating role of job burnout. Importantly, we find a complex set of relationships in our moderated mediation findings, with the mediating influence of cynicism being strongest when an organisation has low knowledge sharing, moderate effects at mean levels of knowledge sharing, but non-significant effects at levels just above the mean (0.2). This means that WLB becomes fundamentally important for top executives even in high knowledge sharing organisations because of the links to lower exhaustion and cynicism. Firms should pay more attention to not only balance issues between executives work and non-work roles, but also through encouraging and developing greater knowledge sharing within their organisation. Combined, these two factors may provide a strong way for organisations to combat the poor retention of top talent. Finally, future studies should look to explore the model towards actual turnover to enhance the practicality of relationships tested, and we encourage further exploration of moderated mediation models. 


\section{References}

Boamah, S. A., \& Laschinger, H. (2016). The influence of areas of worklife fit and work-life interference on burnout and turnover intentions among new graduate nurses. Journal of Nursing Management, 24(2), E164-E174.

Braun, S., \& Peus, C. (2018). Crossover of work-life balance perceptions: Does authentic leadership matter? Journal of Business Ethics, 149(4), 875-893.

Brough, P., Timms, C., O’Driscoll, M. P., Kalliath, T., Siu, O. L., Sit, C., \& Lo, D. (2014). Work-life balance: A longitudinal evaluation of a new measure across Australia and New Zealand workers. The International Journal of Human Resource Management, 25(19), 2724-2744.

Careers New Zealand (2021). Managing Director/Chief Executive. https://www.careers.govt.nz/jobsdatabase/business/management-consulting/managing-directorchief-executive/

Danskin, P., Englis, B. G., Solomon, M. R., Goldsmith, M., \& Davey, J. (2005). Knowledge management as competitive advantage: Lessons from the textile and apparel value chain. Journal of Knowledge Management, 9(2), 91-102.

Dean, J. W., Brandes, P., \& Dharwadkar, R. (1998). Organizational cynicism. Academy of Management Review, 23(2), 341-352.

Euwema, M. C., Kop, N. \& Bakker, A. B. (2004). The behaviour of police officers in conflict situations: How burnout and reduced dominance contribute to better outcomes. Work \& Stress, 18(1), 23-38.

Evans, M. (1985). A Monte Carlo study of the effects of correlated method variance in moderated multiple regression analysis. Organizational Behavior and Human Decision Processes, 36(3), 305-323.

EY, (2015). Global Generations: A Global Study on Work-Life Challenges Across Generations. EYGM Limited.

Ghafoor, A., \& Haar, J. (2020). Organisational-based self-esteem, meaningful work, and creativity behaviours: A moderated mediation model with supervisor support. New Zealand Journal of Employment Relations, 44(3), 11-31.

Griffeth, R. W., Hom, P. W., \& Gaertner, S. (2000). A meta-analysis of antecedents and correlates of employee turnover: Update, moderator tests, and research implications for the next millennium. Journal of Management, 26(3), 463-488.

Haar, J. M. (2013). Testing a new measure of work-life balance: A study of parent and non-parent employees from New Zealand. The International Journal of Human Resource Management, 24, 3305-3324.

Haar, J. \& Brougham, D. (2020). A teams approach towards job insecurity, perceived organisational support and cooperative norms: A moderated-mediation study of individual wellbeing. 
New Zealand Journal of Employment Relations, 46(1): 1-22

International Journal of Human Resource Managent, https://doi.org/10.1080/09585192.2020.1837200

Haar, J., Brougham, D., Roche, M., \& Barney, A. (2017). Servant leadership and work engagement: The mediating role of work-life balance. New Zealand Journal of Human Resource Management, 17(2), 56-72.

Haar, J., Carr, S., Parker, J., Arrowsmith, J., Hodgetts, D. \& Alefaio-Tugia, S. (2018). Escape from working poverty: Steps toward sustainable livelihood. Sustainability, 10(11), 4144. https://doi.org/10.3390/su10114144

Haar, J., Roche, M., \& Brougham, D. (2019). Indigenous Insights into Ethical Leadership: A Study of Māori leaders. Journal of Business Ethics, 160, 621-640.

Haar, J. M., \& White, B. J. (2013) Corporate entrepreneurship and information technology towards employee retention: a study of New Zealand firms. Human Resource Management Journal, 23(1), 109-125.

Hair, J. F., Black, W. C., Babin, B. J., \& Anderson, R. E. (2010). Multivariate Data Analysis: A Global Perspective (7th Edition). Pearson Prentice Hall Publishing, Upper Saddle River.

Harvey, P., \& Martinko, M. J. (2009). An empirical examination of the role of attributions in psychological entitlement and its outcomes. Journal of Organizational Behavior, 30(4), 459-476.

Hayes, A. F. (2018). Partial, conditional, and moderated moderated mediation: Quantification, inference, and interpretation. Communication Monographs, 85(1), 4-40.

Hobfoll, S. E. (2001). The influence of culture, community, and the nested-self in the stress process: Advancing conservation of resources theory. Applied Psychology: An International Review, 50(3), 337-421.

Hobfoll, S. E. (2002). Social and psychological resources and adaptation. Review of General Psychology, 6(4), 307-324.

Hobfoll, S. E., Halbesleben, J., Neveu, J. P., \& Westman, M. (2018). Conservation of resources in the organizational context: The reality of resources and their consequences. Annual Review of Organizational Psychology and Organizational Behavior, 5, 103-128.

Hom, P. W., Roberson, L., \& Ellis, A. D. (2008). Challenging conventional wisdom about who quits: Revelations from corporate America. Journal of Applied Psychology, 93(1), 1-34.

Husted, K. \& Michailova, S. (2002). Diagnosing and fighting knowledge sharing hostility. Organizational Dynamics, 31(1), 60-73.

Husted, K., Michailova, S., Minbaeva, D. B., \& Pedersen, T. (2012). Knowledge-sharing hostility and governance mechanisms: An empirical test. Journal of Knowledge Management, 16(5), 754-773. 
Kelloway, E. K., Gottlieb, B. H., \& Barham, L. (1999). The source, nature, and direction of work and family conflict: A longitudinal investigation. Journal of Occupational Health Psychology, 4(4), 337346.

Laschinger, H. K. S., \& Fida, R. (2014). A time-lagged analysis of the effect of authentic leadership on workplace bullying, burnout, and occupational turnover intentions. European Journal of Work and Organizational Psychology, 23(5), 739-753.

Leiter, M. P., \& Maslach, C. (2004). Areas of worklife: A structured approach to organizational predictors of job burnout. In, Perrewé, P. L., \& Ganster, D. C. (Eds.), Emotional and Physiological Processes and Positive Intervention Strategies Research in Occupational Stress and Well Being, Volume 3, (pp. 91-134). Elsevier JA.

Leiter, M. P., \& Maslach, C. (2009). Nurse turnover: The mediating role of burnout. Journal of Nursing Management, 17(3), 331-339.

Maslach, C., \& Jackson, S. (1981). Measurement of experienced burnout. Journal of Occupational Behavior, 2(2), 99-113.

Ng, T. W., \& Feldman, D. C. (2008). Long work hours: A social identity perspective on meta-analysis data. Journal of Organizational Behavior, 29(7), 853-880.

Park, T. Y., \& Shaw, J. D. (2013). Turnover rates and organizational performance: A metaanalysis. Journal of Applied Psychology, 98(2), 268-309.

Pfeffer, J. (2001). Fighting the war for talent is hazardous to your organization's health. Organizational Dynamics, 29(4), 248-259.

Podsakoff, P. M., MacKenzie, S. B., Lee, J. Y., \& Podsakoff, N. P. (2003). Common method biases in behavioral research: A critical review of the literature and recommended remedies. Journal of Applied Psychology, 88(5), 879-903.

Roche, M. \& Haar, J. M. (2013). Leaders life aspirations and job burnout: A self determination theory approach. Leadership \& Organization Development Journal, 34(6), 515-531.

Russo, M., Shteigman, A., \& Carmeli, A. (2016). Workplace and family support and work-life balance: Implications for individual psychological availability and energy at work. The Journal of Positive Psychology, 11(2), 173-188.

Sharma, R. R., \& Cooper, C. L. (2016). Executive Burnout: Eastern and Western Concepts, Models and Approaches for Mitigation. Emerald Group Publishing.

Surienty, L., Ramayah, T., Lo, M. C., \& Tarmizi, A. N. (2014). Quality of work life and turnover intention: A partial least square (PLS) approach. Social Indicators Research, 119(1), 405-420. 
Tepper, B. J. (2000). Consequences of abusive supervision. Academy of Management Journal, 43(2), 178-190.

Tett, R. P., \& Meyer, J. P. (1993) Job satisfaction, organizational commitment, turnover intention, and turnover: Path analyses based on meta-analytic findings. Personnel Psychology, 46(2), 259-293.

Umene-Nakano, W., Kato, T. A., Kikuchi, S., Tateno, M., Fujisawa, D., Hoshuyama, T., \& Nakamura, J. (2013). Nationwide survey of work environment, work-life balance and burnout among psychiatrists in Japan. PloS ONE, 8(2), e55189. https://doi.org/10.1371/journal.pone.0055189

Walter, S. L., Seibert, S. E., Goering, D., \& O’Boyle, E. H. (2018). A tale of two sample sources: Do results from online panel data and conventional data converge? Journal of Business and Psychology 1-28. https://doi.org/10.1007/s10869-018-9552-y

Wayne, S. J., Lemmon, G., Hoobler, J. M., Cheung, G. W., \& Wilson, M. S. (2017). The ripple effect: A spillover model of the detrimental impact of work-family conflict on job success. Journal of Organizational Behavior, 38(6), 876-894.

Williams, L. J., Vandenberg, R., \& Edwards, J. R. (2009). Structural equation modelling in management research: A guide for improved analysis. The Academy of Management Annals, 3(1), 543-604.

Wright, T. A., \& Cropanzano, R. (1998). Emotional exhaustion as a predictor of job performance and voluntary turnover. Journal of Applied Psychology, 83(3), 486-493. 